\title{
Evolution of Microstructure and Toughness in 2.25Cr-1Mo Steel Welds
}

\author{
Ahmed Elrefaey ${ }^{* a}$, Yashar Javadi ${ }^{\mathbf{a}}$, John A. Francis ${ }^{\mathbf{a}}$, Mark D. Callaghan ${ }^{\mathbf{a}}$ and Andrew J. Leonard ${ }^{\mathbf{b}}$ \\ ${ }^{a}$ School of Mechanical, Aerospace and Civil Engineering, The University of Manchester, U.K. \\ ${ }^{b}$ BP Exploration Operating Company Ltd., Sunbury on Thames, U.K. \\ ${ }^{*}$ Corresponding Author: Ahmed.Elrefaey@Swansea.ac.uk \\ * Corresponding Author Permanent address: CMRDI, Egypt, Cairo, Helwan
}

\begin{abstract}
In oil and gas and other industries, valve bodies are often manufactured using a $2.25 \mathrm{Cr}-1 \mathrm{Mo}$ steel which, if welded, requires post-weld heat treatment (PWHT) in order to restore toughness. The safe operation and longterm integrity of such welds is critically dependent on achieving adequate toughness across the welded joint. In this work, mock-ups were manufactured for the purpose of assessing the effects of the weld heat input on toughness. The assessment was made by carrying out crack tip opening displacement (CTOD) and Charpyimpact tests in different metallurgical regions and, after testing, by examining the fracture surfaces using optical- and scanning-electron microscopy, and energy-dispersive spectroscopy. There did not appear to be an effect of weld heat input on toughness at a test temperature of $+20^{\circ} \mathrm{C}$. However, for the case where a high weld heat input was employed, the toughness of the weld metal dropped by close to $50 \%$ when the temperature was decreased to $-20^{\circ} \mathrm{C}$. These results suggest that inadequate control of the welding process may lead to significant variability in weld toughness, and that high weld heat inputs should be avoided when welding or buttering $2.25 \mathrm{Cr}-1 \mathrm{Mo}$ steel components.
\end{abstract}

\section{Keywords}

Buttering layer, dissimilar metal weld, ductile-to-brittle transition, fracture toughness, heat-affected zone, subsea systems. 


\section{Introduction}

Ferritic Cr-Mo F22 forging steels are frequently used in subsea service in the oil and gas industry, particularly for components such as valve bodies. This steel possesses high hardenability and requires post weld heat treatment (PWHT) in order to satisfy both the strength and hardness requirements within the heat-affected zone (HAZ), and to reduce welding residual stresses. Valve bodies are usually welded to pipes on site so, in order to enable PWHT of the valve body, a weld-buttering layer is deposited on to the forging steel in a workshop, thereby creating a dissimilar metal weld. After buttering, the forging undergoes PWHT and it is then ready to be transported to site, and it may be welded to pipeline steels in the field without any further deterioration in properties. Since pipeline steels generally do not require PWHT, no further heat treatments are required.

When alloy 625 is used as the buttering material, a number of different processes take place during PWHT which benefit the resulting joint, such as the tempering of the microstructure and the alleviation and redistribution of residual stresses. However, a narrow band of martensite may form along the fusion boundary due to the transition in composition between the F22 steel and a Ni-based filler material, producing a region that will exhibit high hardness relative to the neighbouring steel and diluted weld metal [1]. PWHT can also promote the formation of $\mathrm{M}_{7} \mathrm{C}_{3}$ carbides, which can potentially exacerbate hydrogen embrittlement. Some degree of de-carburisation of the HAZ in the F22 steel may also be expected, leading to carbon enrichment of the adjacent Cr-rich weld metal. These phenomena may all contribute to the formation of zones with increased strength and decreased toughness $[1,2]$, which can be problematic from a structural integrity standpoint. On this basis, there has been a trend towards moving away from nickel-based buttering materials to alternative low-alloy steel (LAS) compositions, since the microstructures produced at the interface within F22-LAS weldments are preferred [3].

Another critical concern in relation to the use of F22 steel in subsea applications is the potential for exposure of the steel to sour production fluid. Under such conditions, exposure to hydrogen sulphide $\left(\mathrm{H}_{2} \mathrm{~S}\right)$ can lead to failure by sulphide stress corrosion cracking if a susceptible microstructure is present. Accordingly, the material hardness in the HAZ, resulting from the cladding process, plays a critical role in determining the susceptibility to such failures [4]. To this end, the National Society of Corrosion Engineers (NACE) and the 
International Organization for Standardization (ISO) have established guidelines that require the maximum hardness of the HAZ to not exceed $22 \mathrm{HRC}$ (or $250 \mathrm{VHN}$ ) in certain situations [5].

Although LAS buttering layers are now frequently employed in welded joints of this type, there have been some observations within the oil and gas industry of variability in toughness at the F22 steel/butter interface. To date, the causes of this variability have remained unclear. It is possible that such variability in toughness is linked to changes in the welding parameters that are employed to deposit the buttering layer. The primary aim of this work is to establish whether a change in the process parameters could play some role in contributing to the variability in toughness, given that the choice of process parameters will impact directly on the severity of welding thermal cycles. In this article, we describe the manufacture of weld-buttered mock-ups in F22 steel, and the subsequent characterisation of toughness in the weld metal and at the F22-LAS interface.

\section{Experimental work}

\subsection{Materials and welding procedure}

The base metal (BM) used in this study was ASTM A182 F22 forging steel, in the form of plates with dimensions of $400 \mathrm{~mm} \cdot 200 \mathrm{~mm} \cdot 30 \mathrm{~mm}$. The plates were supplied in the normalized and tempered condition. The weld filler material designation was Oerlikon S3 NiMo-1 (AWS A5.23: EF3; EN 756 S3Ni1Mo) and the wire diameter was $2.4 \mathrm{~mm}$, and this was used in conjunction with Oerlikon OP 121TT welding flux, which has a low hydrogen content and is resistant to moisture pick-up in workshop environments. This combination of filler wire and flux is intended for high integrity welds that must retain toughness at low temperatures. The chemical compositions for the F22 steel and the filler metal are summarized in Table 1.

In preparation for buttering, the edges of the plates were machined to produce a bevel at an angle of $30^{\circ}$, and the bevelled surfaces were cleaned with a steel brush to remove the oxide layer and other contaminants. After cleaning, samples were positioned for welding and were restrained with clamps, as is shown in Fig. 1. A mild steel backing plate was employed in order to support the buttering layer during the deposition process, and this plate was removed by machining at a later stage in the manufacturing sequence. A submerged arc welding system was used to manufacture the weld mock-ups. A torch angle of $5^{\circ}$ off vertical was used to perform the 
first weld run in each layer of buttering. A summary of the buttering parameters is included in Fig. 1. Four samples were manufactured in total, with two different heat inputs; two samples were manufactured with a heat input of $2.3 \mathrm{~kJ} / \mathrm{mm}(\mathrm{M} 1)$ while the other two had a heat input of $1.1 \mathrm{~kJ} / \mathrm{mm}$ (M2). This change in weld heat input was achieved by changing the welding speed from 250 to $500 \mathrm{~mm} / \mathrm{min}$. Sample M1 was buttered by applying 10 layers of weld beads with 124 weld beads in total, while sample M2 was buttered using 12 layers of weld beads and 186 beads in total. Cooling times with the different heat inputs were simultaneously recorded by attaching thermocouples as close as possible to the weld beads. Since the focus of this study was to investigate material toughness in the vicinity of the F22 steel/weld butter interface, the test pieces were not subsequently welded to other components. Nevertheless, PWHT was carried out in air to temper the microstructures, decrease the hardness at the F22/buttering interface, and to relieve residual stresses. The PWHT procedure consisted of heating the samples at a rate of $32^{\circ} \mathrm{C}$ per hour to a hold temperature of $630^{\circ} \mathrm{C}$, which was maintained for 7 hours and 15 minutes, and then cooling in air to ambient temperature. Table 1: Chemical analyses for base and filler materials.

\begin{tabular}{|l|r|r|r|r|r|r|l|l|l|}
\hline & \multicolumn{7}{|c|}{ Typical chemical composition (wt.\%) } \\
\cline { 2 - 11 } & \multicolumn{1}{|c|}{$\mathrm{C}$} & $\mathrm{Si}$ & $\mathrm{Mn}$ & $\mathrm{Cr}$ & \multicolumn{1}{l|}{ Mo } & Ni & P & $\mathrm{S}$ & Fe \\
\hline ASTM A182 F22 & 0.14 & 0.19 & 0.57 & 2.5 & 1.05 & 0.48 & 0.005 & 0.002 & Bal. \\
\hline OE-S3 NiMo-1 & 0.07 & 0.3 & 1.5 & - & 0.5 & 1.0 & N.A. & N.A. & Bal. \\
\hline
\end{tabular}

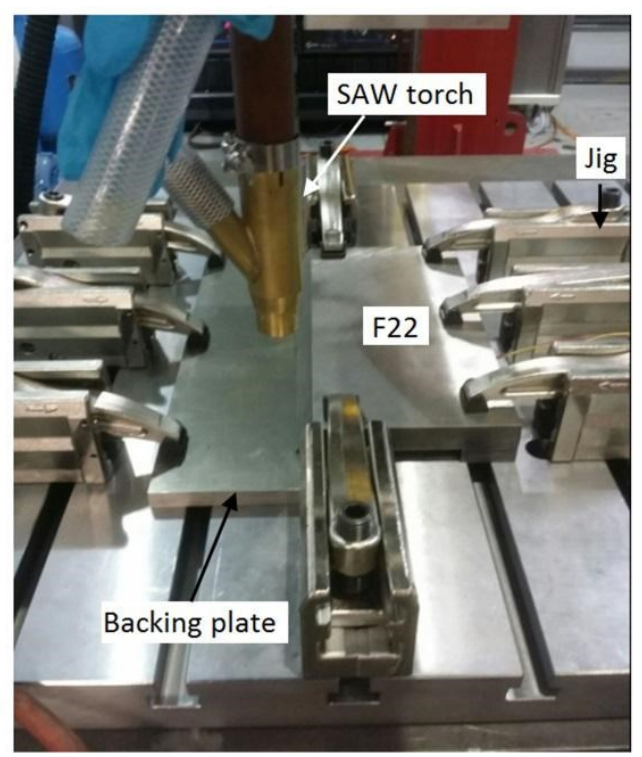

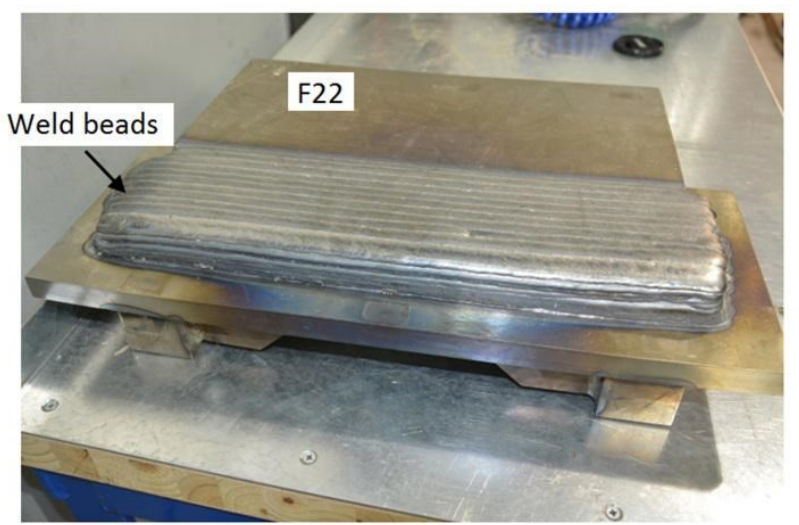

Wellding Current $350 \mathrm{~A}$,

Welding Speed: 250 and $500 \mathrm{~mm} / \mathrm{min}$ Welding Voltage: $27 \mathrm{~V}$ $180^{\circ} \mathrm{C}<$ Preheating Temperature $<240{ }^{\circ} \mathrm{C}$ $150{ }^{\circ} \mathrm{C}<$ Interpass Temperature $<180{ }^{\circ} \mathrm{C}$ 12 Thermocouples were installed

Fig. 1: Welding set-up and summary of welding parameters. 


\subsection{Metallography}

Cross-sectioning of the samples was performed for metallographic analysis to identify the different weld zones and to check for the presence of weld defects such as porosity and lack of fusion. The samples were prepared according to standard metallographic practice (ASTM E3-11), and etched with 2\% Nital. The microstructures of different zones of interest, such as the BM, HAZ and fusion zone (FZ) were analysed on a Keyence VHX-5000 microscope. In addition, a Zeiss EVO 60 scanning electron microscope (SEM) equipped with an energy dispersive X-ray (EDX) spectrometer was employed to investigate the intermetallic phases and fracture morphology.

\subsection{Mechanical Testing}

A range of mechanical testing methods was employed to characterise the performance of the weldments as a function of buttering heat input. Tensile specimens were prepared exclusively from parent material and tested in accordance with ISO 6892-1:2009 Method B. All specimens were machined to a round cross-section with a nominal gauge diameter of $6.4 \mathrm{~mm}$, with a parallel length of $38.4 \mathrm{~mm}$. The axis of the tensile specimens was orientated so that it was perpendicular to the welding direction and within the plane of the plate. Charpy impact specimens were prepared and tested in accordance with BS EN ISO 148-1:2010. All Charpy impact specimens were machined to the standard dimensions of $55 \mathrm{~mm} \cdot 10 \mathrm{~mm} \cdot 10 \mathrm{~mm}$ with a $2 \mathrm{~mm}$ deep Veenotch. Fracture toughness specimens were also prepared and tested in accordance with ISO 15653:2010. All fracture toughness samples were machined to the B - B Single-Edge Notched Beam (SENB) configuration with nominal dimensions of $26.25 \mathrm{~mm}(\mathrm{~B}) \cdot 26.25 \mathrm{~mm}(\mathrm{~W})$, with a length of $163 \mathrm{~mm}$. The tests were conducted on specimens with a through-thickness notch (NP orientation) and on specimens with notches originating from the plate surface (NQ orientation), where the notation is described in ISO 15653:2010. The orientations for the different specimens are represented schematically in Fig. 2, while the full test matrix is summarised in Table 2.

The fracture toughness specimens were notched using the electric-discharge machining (EDM) process in conjunction with a wire that was $0.25 \mathrm{~mm}$ in diameter. To aid pre-cracking, all specimens were reverse loaded before commencing the fatigue crack growth. Those specimens targeting the fusion line were notched from 
the root side of the weld (i.e. from within the F22 steel), with the machined notch terminating just short of the fusion line, so that the pre-crack could, in principle, intercept the fusion line at a nominal target depth (a/W) of 0.5. This option was pursued on the basis that, during subsequent testing, it might have lead to the crack propagating through the microstructural zone (in the vicinity of the fusion zone) that had the lowest toughness. All specimens were pre-cracked and tested at ambient temperature using rigid three-point bend rigs with free moving outer rollers. After pre-cracking, knife-edges were machined at the crack mouth to enable a clip gauge to be fitted to monitor the crack mouth opening. After testing, the length of the pre-crack was measured optically, and the crack tip opening displacement (CTOD) was calculated by comparing the load with the output from the clip gauge. Finally, the specimens targeting the fusion line were vertically sectioned to determine the position of the pre-crack. In general, the tips of the pre-cracks were found to be within 0.5 $\mathrm{mm}$ of the fusion line.

Hardness measurements were made using a Struers Durascan 80 automated hardness tester. Mapping of the hardness distributions was carried out using a load of $0.5 \mathrm{~kg} \square \mathrm{f}$ at intervals of $0.5 \mathrm{~mm}$ across the BM, HAZ, and FZ, from the top to the bottom of the cross section in each case.
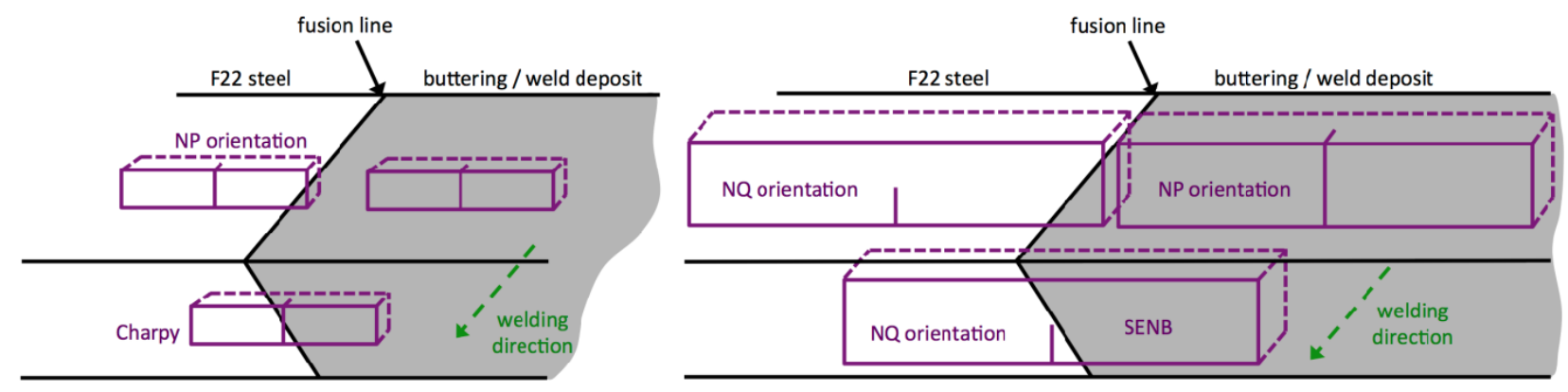

Fig. 2: Schematic representation of orientations for Charpy (left) and SENB (right) specimens. All Charpy coupons had the NP orientation. For the SENB specimens at the fusion line and in the parent material, cracks nominally propagated in the through-thickness direction, from the bottom towards the top of the test piece. In contrast, cracks in the weld metal SENB specimens nominally propagated parallel to the welding direction, with a view to obtaining properties that were averaged across several layers of weld metal. 


\section{Results and Discussion}

\subsection{Microstructural features}

After buttering of the samples, one slice was extracted from the mid-length position of each test piece for the purpose of carrying out metallographic investigations and hardness measurements. Macrograph cross-sections from samples M1 and M2, and higher magnification views of the F22/buttering interface, are shown in Fig. 3. Sound welds were produced without any lack of fusion or any visible defects. It should be noted that the dark bands in the vicinity of the fusion line are a consequence of etching contrast, and that full continuity of material was always maintained. The weld beads were large in the case of sample M1, when compared to those in sample M2. Furthermore, the HAZ in the high heat input (HHI) buttering sample extended almost 3.5 $\mathrm{mm}$ from the fusion boundary, whereas for the low heat input (LHI) sample the HAZ was confined to within $2.6 \mathrm{~mm}$ of the fusion boundary, as can be seen in Figs. $3 \mathrm{c}$ and $3 \mathrm{~d}$.

Table 2: Test matrix for the assessment of toughness in weld-buttered test pieces.

\begin{tabular}{|c|c|c|c|c|c|c|c|}
\hline Sample Type & $\begin{array}{c}\text { Specimen } \\
\text { Type }\end{array}$ & Output & \multicolumn{2}{|c|}{ Test } & $\begin{array}{c}\text { Test } \\
\text { Specification }\end{array}$ & $\begin{array}{c}\text { Orientation / } \\
\text { Position }\end{array}$ & $\begin{array}{c}\text { Required No. of } \\
\text { Valid Tests }\end{array}$ \\
\hline \multirow[t]{3}{*}{$\begin{array}{c}\text { F22 Parent } \\
\text { Material }\end{array}$} & $\begin{array}{l}\text { Round } \\
\text { Tensile }\end{array}$ & $\begin{array}{c}\text { Stress vs. } \\
\text { Strain }\end{array}$ & \multicolumn{2}{|c|}{ Ambient } & ISO 6892-1 & Transverse & 5 \\
\hline & Charpy & Energy $(\mathrm{J})$ & \multicolumn{2}{|c|}{ Ambient } & ISO 148 & PM-NP & 5 \\
\hline & SENB & CTOD & \multicolumn{2}{|c|}{ Ambient } & ISO 15653 & PM-NQ & 3 \\
\hline \multirow[t]{4}{*}{ Weld butter } & \multirow[t]{2}{*}{ Charpy } & \multirow[t]{2}{*}{ Energy $(\mathrm{J})$} & $20^{\circ} \mathrm{C}$ & $-20^{\circ} \mathrm{C}$ & \multirow[t]{2}{*}{ ISO 148} & WM-NP & 5 \\
\hline & & & $20^{\circ} \mathrm{C}$ & $-20^{\circ} \mathrm{C}$ & & FL-NP & 5 \\
\hline & \multirow[t]{2}{*}{ SENB } & \multirow[t]{2}{*}{ CTOD } & $20^{\circ} \mathrm{C}$ & $-20^{\circ} \mathrm{C}$ & \multirow[t]{2}{*}{ ISO 15653} & WM-NP & 3 \\
\hline & & & $20^{\circ} \mathrm{C}$ & $-20^{\circ} \mathrm{C}$ & & FL-NQ & 3 \\
\hline \multirow[t]{4}{*}{ Weld butter } & \multirow[t]{2}{*}{ Charpy } & \multirow[t]{2}{*}{ Energy $(\mathrm{J})$} & $20^{\circ} \mathrm{C}$ & $-20^{\circ} \mathrm{C}$ & \multirow[t]{2}{*}{ ISO 148} & WM-NP & 5 \\
\hline & & & $20^{\circ} \mathrm{C}$ & $-20^{\circ} \mathrm{C}$ & & FL-NP & 5 \\
\hline & \multirow[t]{2}{*}{ SENB } & \multirow[t]{2}{*}{ CTOD } & $20^{\circ} \mathrm{C}$ & $-20^{\circ} \mathrm{C}$ & \multirow[t]{2}{*}{ ISO 15653} & WM-NP & 3 \\
\hline & & & $20^{\circ} \mathrm{C}$ & $-20^{\circ} \mathrm{C}$ & & FL-NQ & 3 \\
\hline
\end{tabular}



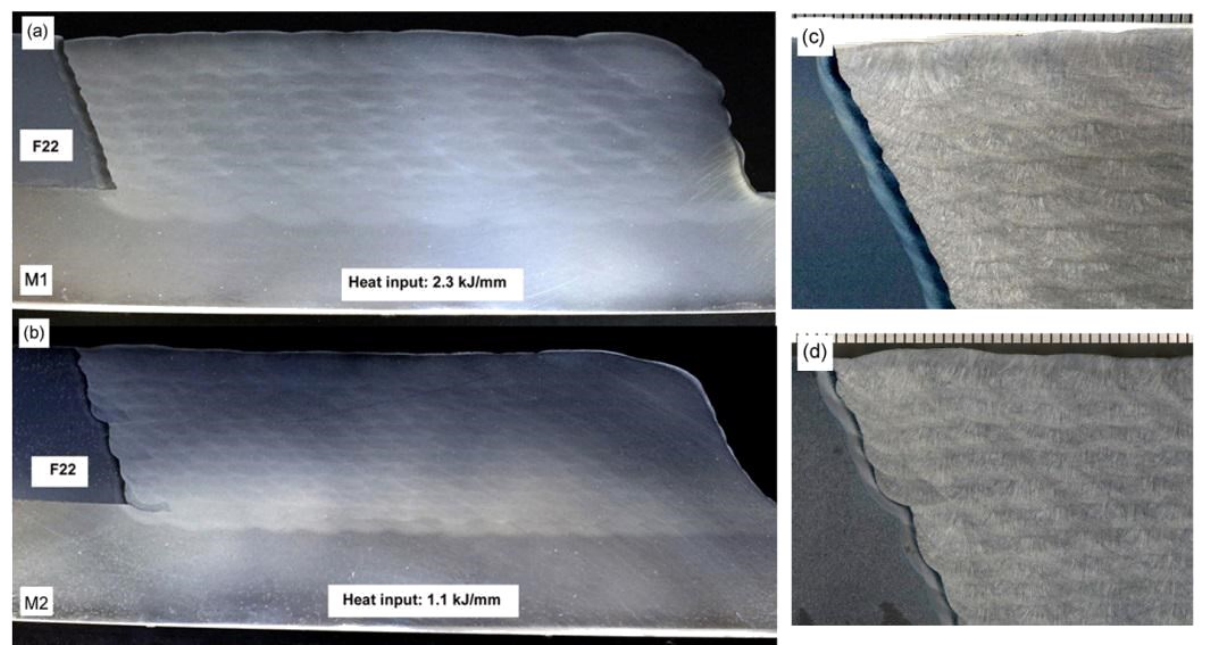

Fig. 3: Macrograph sections extracted from samples M1 and M2: (a) buttering at HHI (2.3 kJ/mm); (b) buttering at LHI $(1.1 \mathrm{~kJ} / \mathrm{mm})$; and higher magnification views of the buttering interface in sample M1 (c) and sample M2 (d).

Detailed microstructural features from sample M1 are shown in Fig. 4. The coarse grained region is present within the HAZ due to the peak temperature during the welding thermal cycle being high enough for significant austenite grain growth to occur. In this region, the stabilizing carbides dissolve on heating in the temperature range between 1000 and $1050^{\circ} \mathrm{C}$, allowing significant grain growth in areas that experience a peak temperature above these values [6]. This region is referred to as the coarse-grained heat affected zone (CGHAZ). In the same way, the fine-grained HAZ undergoes a transformation to austenite but the peak temperatures are insufficient for any grain growth to occur. As a result of the refined austenite grains, the final microstructure after cooling is also refined. This region is referred to as the fine-grained heat affected zone (FGHAZ). Adjacent to the FGHAZ, there is a region where the material underwent sufficient heating to only partially transform to austenite. This region is referred to as the intercritical heat affected zone (ICHAZ). Meanwhile, in the region adjacent to the ICHAZ, where there is no transformation to austenite because the peak temperature was lower than that needed for the austenite transformation to commence, the thermal cycle can still change some of the microstructural features, such as the grain size or the morphology of secondary phases. This region is referred to as the tempered heat affected zone (THAZ). 
The microstructure of the as-received material is shown in Fig. 4e. It consisted of coarse bainite ( $90 \%)$ and small ferrite grains. The ferrite grain size was less than $10 \mu \mathrm{m}$. In the HHI sample (M1), the structure within the CGHAZ was also predominantly bainite with some small regions of ferrite (see Fig. 4b). The ferrite appears as the light-etching phase, and is likely to be pro-eutectoid ferrite, which differs in morphology from the ferrite in a bainitic structure. The FGHAZ contained similar proportions of $(\sim 85 \%)$ bainite and $(\sim 15 \%)$ pro-eutectoid ferrite. In the ICHAZ, slightly coarser ferrite grains were observed, as can be seen in Fig. 4d. Meanwhile, the corresponding microstructures for the LHI joint were similar to those for the HHI joint, with exceptions including the smaller extent of the HAZ, and the fact that the bainite in the CGHAZ for the HHI joint appeared to be fully tempered.

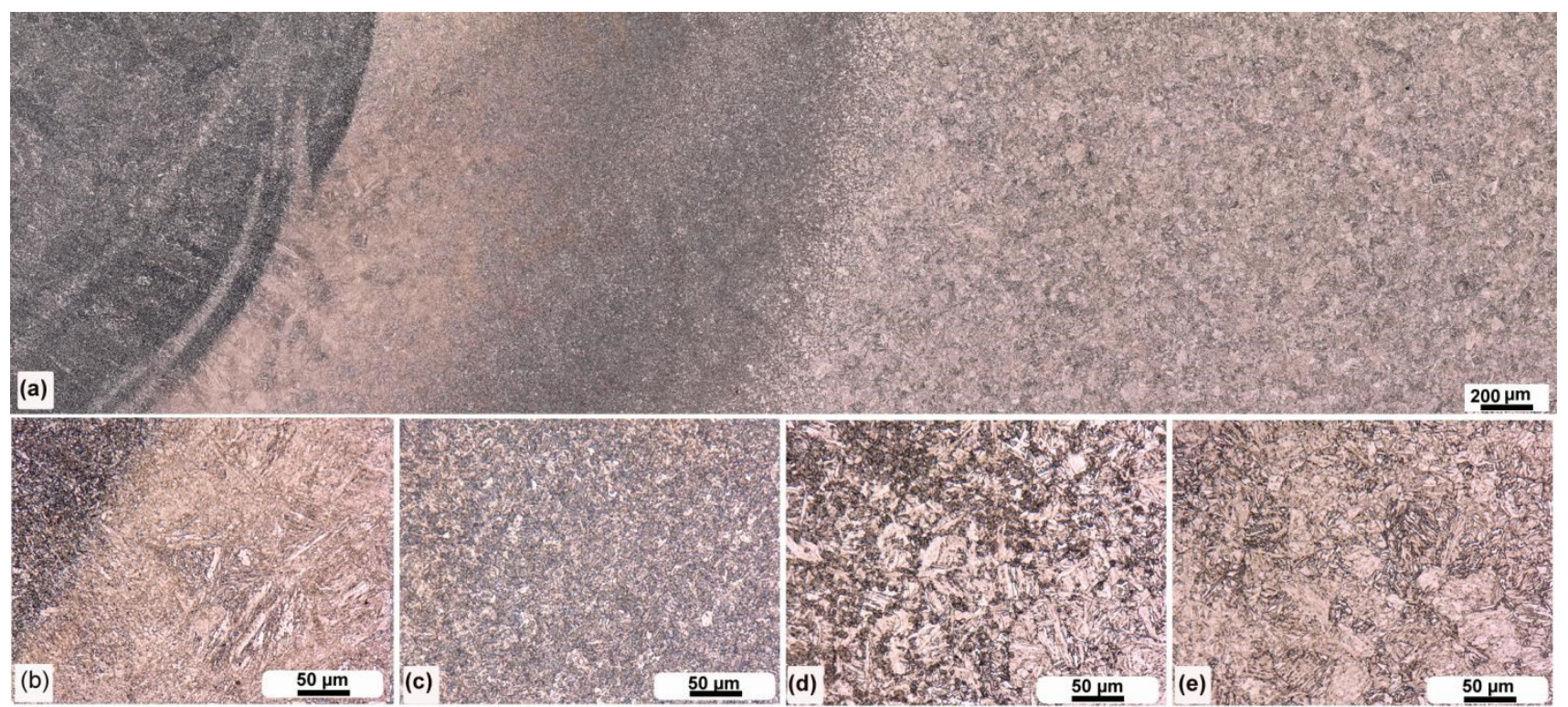

Figure 4: As-welded microstructures within sample M1: (a) low-magnification view across fusion boundary and HAZ; (b) FZ/CGHAZ interface; (c) FGHAZ; (d) ICHAZ; (e) unaffected base metal.

The microstructures within the weld regions in samples M1 and M2 underwent some degree of tempering owing to the thermal cycles that were associated with successive weld passes $[7,8]$. Full or partial reaustenitisation of the material may occur in these cycles, and different transformation products may be produced upon cooling after re-austenitisation. It is important for the PWHT operation to temper all regions across the weldment uniformly, and for it to decrease the hardness at the fusion boundary. PWHT led to growth of the ferrite laths, which also became more polygonised, and a decrease in delineation within the 
previously bainitic structure. Optical- and scanning electron microscopy are often unable to resolve the details of the carbide precipitate morphology, or identify other fine precipitates. However, it is expected that the driving force for further carbide precipitation during PWHT would have been low, since many carbides will have precipitated during the first austenite to bainite transformation, while others will have precipitated during the tempering processes associated with subsequent welding thermal cycles. This will have reduced the concentration of carbon dissolved in the matrix, thereby lowering the driving force for further precipitation. However, some changes in microstructure during PWHT could be observed, and these can be seen in Fig. 5. These changes are in consistent with those reported in the literature [9-12]. The average size of laths/grains and carbide particles increased, and the carbides coarsened as tempering progressed.
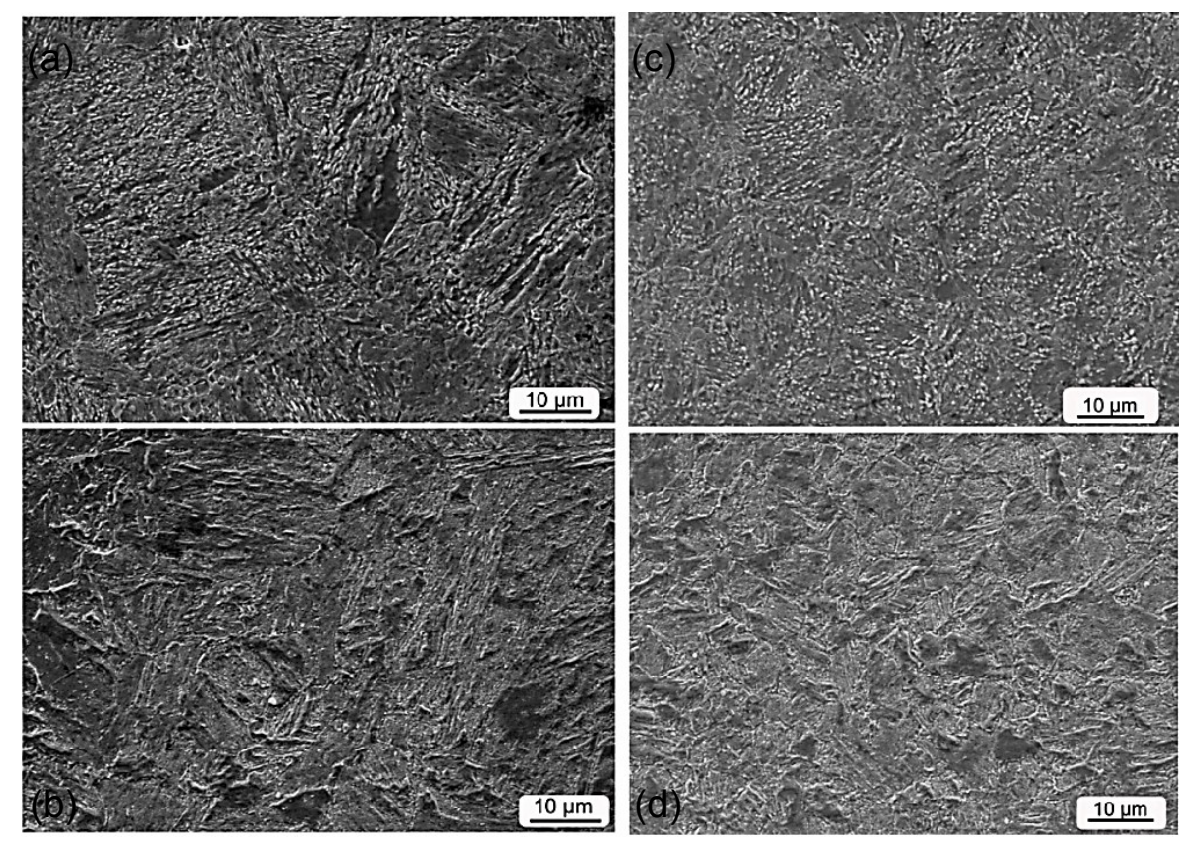

Figure 5: SEM images captured from weld-buttered sample M1: (a) CGHAZ before PWHT; (b) CGHAZ after PWHT; (c) FGHAZ before PWHT; (d) FGHAZ after PWHT.

Large columnar grains were observed in the fusion zone. The thermal cycles associated with later weld passes had a tendency to re-austenitise previously deposited weld metal, leading to refinement of the structure. Within the weld metal region, the presence of an alternating sequence of columnar and refined prior-austenite grains was observed, with ambient-temperature structures comprising coarse- and fine-grained ferrite and pearlite. This pattern confirmed that subsequent welding thermal cycles led to significant microstructural changes. Increasing the heat input increased the extent of individual weld beads (see Figs. $3 c \& d$ ). Within the 
weld beads themselves, an increase in the heat input led to a greater proportion of the columnar structure being transformed into a refined equiaxed structure [13], as can be seen in Fig. 6.
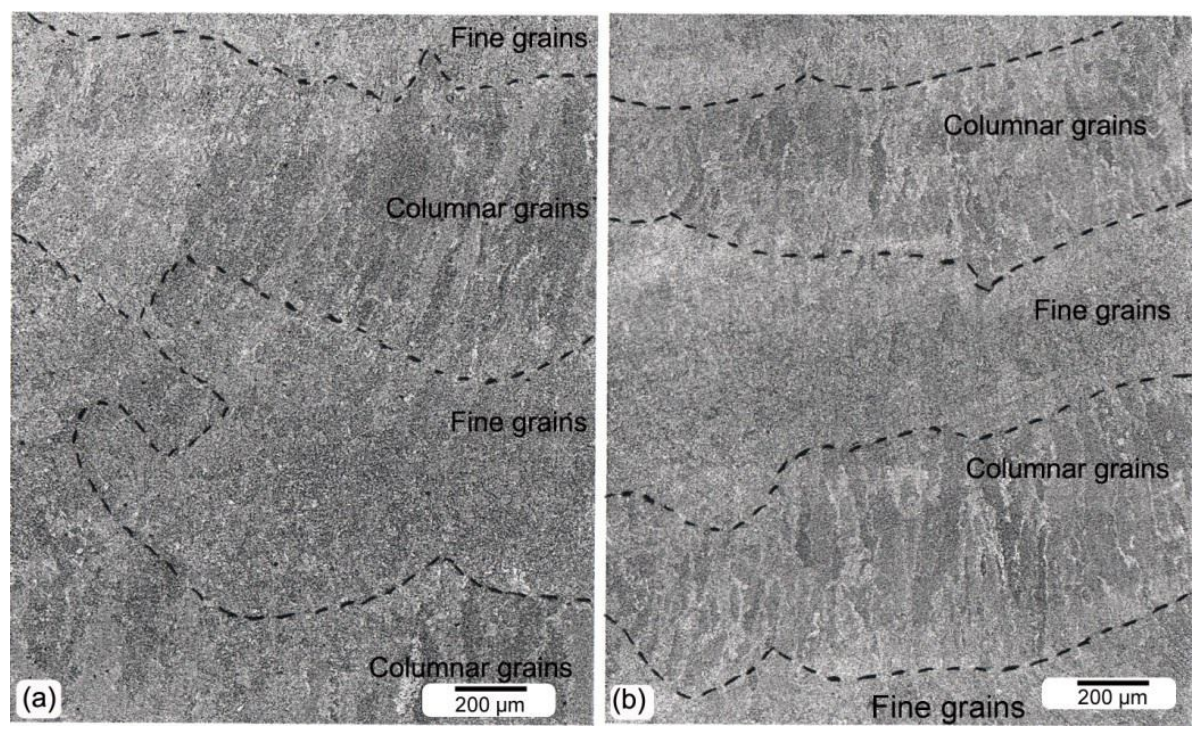

Fig. 6: Microstructures within the fusion zone: (a) buttering with low heat input; (b) buttering with high heat input.

\subsection{Mechanical properties}

Hardness maps are provided in Fig. 7 for sample M1 both before and after PWHT. This sample was buttered using a HHI. The HAZ was harder than both the BM and the FZ in both conditions. The heating and cooling cycles within the HAZ resulted in an almost fully bainitic structure, which led to relatively high HAZ hardness values. Furthermore, the CGHAZ had a higher hardness than the FGHAZ, irrespective of the heat input, due to the formation of fine bainitic structures within relatively large prior-austenite grains. Hardness peaks in the CGHAZ are known be associated with the higher hardenability that results from a larger prioraustenite grain size [14]. PWHT led to a reduction in HAZ hardness, to values slightly higher than those for the BM and FZ. The HAZs associated with later passes were generally harder than those for weld beads in the first layer of buttering that was deposited, owing to the higher cooling rates that would have been experienced (larger heat sink) and a reduction in the tempering effects associated with the deposition of subsequent layers of metal.

In Fig. 8, the hardness distributions are correlated with microstructural features for both the HHI and LHI weld mock-ups. Hardness values decreased with decreases in cooling rate (e.g. for the HHI case). This trend is 
consistent with increased coarsening of microstructures and decreased dislocation densities, as transformations take place over longer times when the cooling rate decreases. Indeed, the high cooling rate sample (LHI) exhibited noticeably higher as-welded hardness values than the low cooling rate sample (HHI). It is worth mentioning here that the cooling time between 800 and $500^{\circ} \mathrm{C}$ for sample M1 was $19 \mathrm{~s}$. In contrast, the corresponding time for sample M2 was $8 \mathrm{~s}$, as determined from thermocouple data obtained from locations as close as possible to the F22-LAS fusion boundary. The maximum hardness values that were recorded for the HHI and LHI test pieces after PWHT were 269 and $301 \mathrm{HV}$, respectively.
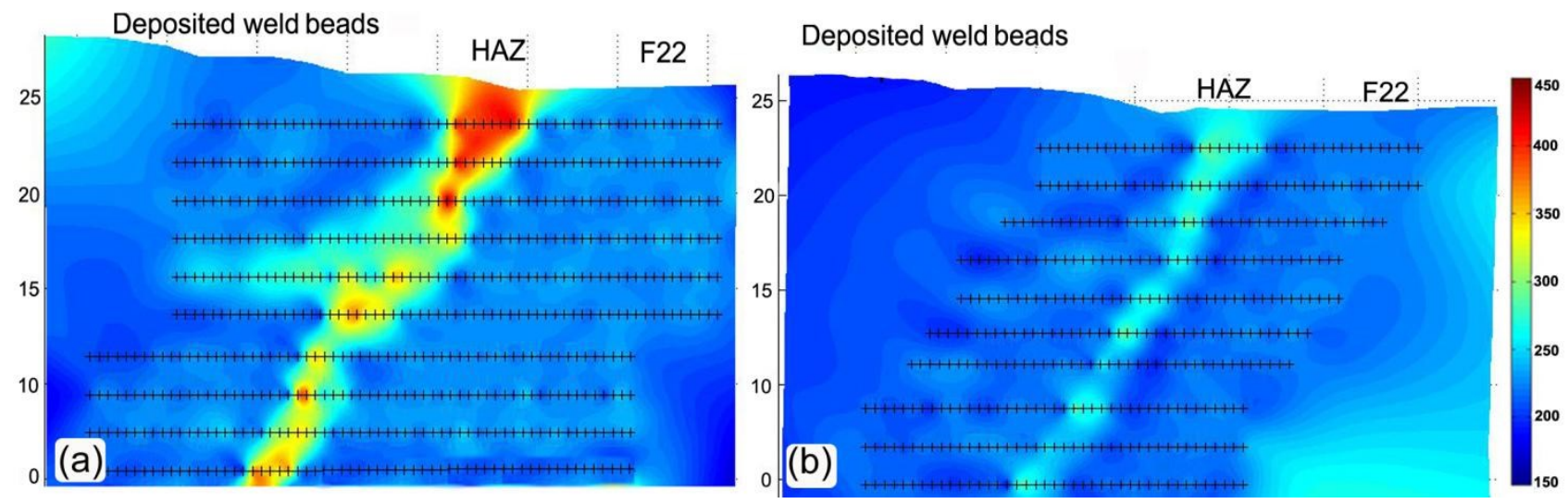

Figure 7: Hardness maps for sample M1 (HHI) before (a) and after (b) PWHT. The black lines in each figure reveal the locations at which the hardness was measured.
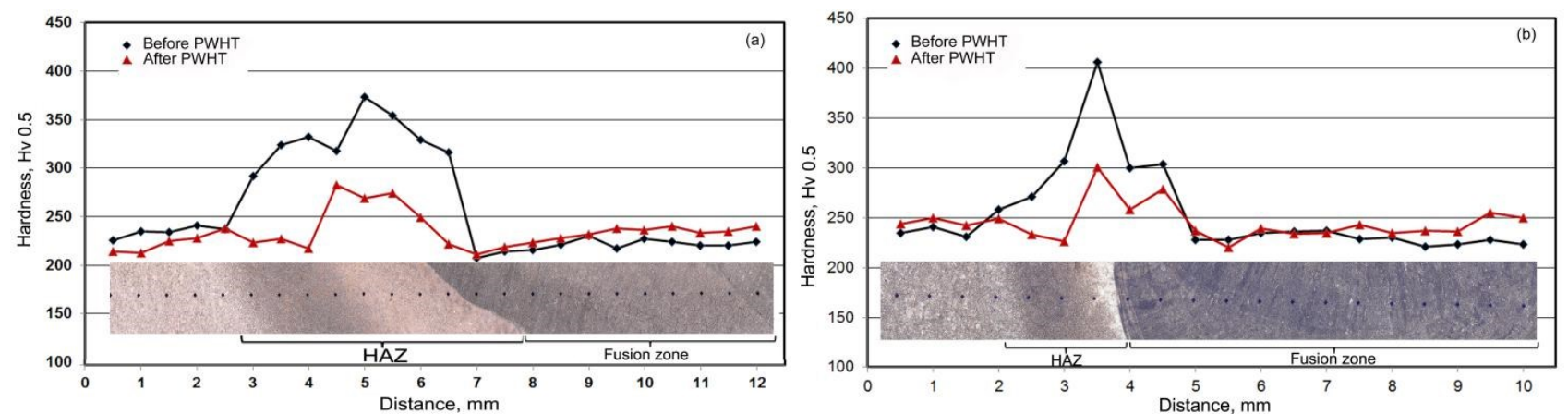

Figure 8: Hardness distributions across the F22-LAS buttering interface for (a) the HHI sample and (b) the LHI sample.

The results of the tensile tests carried out on the BM before and after PWHT are listed in Table 3. PWHT led to decreases in the $0.2 \%$ proof stress and in the ultimate tensile strength (UTS). There were no noticeable 
changes in elongation. The results of the CTOD and Charpy impact tests are summarized in Table 4, which includes results obtained at $20^{\circ} \mathrm{C}$ and at $-20^{\circ} \mathrm{C}$. CTOD testing for fracture toughness can be considered to be preferable to Charpy impact testing, since full-thickness fracture tests can reduce some of the uncertainties associated with material thickness, and CTOD tests involve the production of a real crack, as opposed to a machined notch, and they also utilise a slower deformation rate $[15,16]$. The CTOD test results at a temperature of $20^{\circ} \mathrm{C}$ suggest that there is no clear effect of heat input on fracture toughness. The two welded joints both achieved fracture toughness values that were similar to (or superior to) those for the parent metal. The Charpy impact test results at $-20^{\circ} \mathrm{C}$ reveal that the absorbed energy decreased in all cases when compared to the tests carried out at $20^{\circ} \mathrm{C}$, typically by $\sim 15 \%$. By far, the most pronounced drop occurred in the weld metal for the high heat input weld, where the impact energy reduced by approximately $50 \%$. The scatter in the recorded values for impact energy is also much greater in the weld metal than it is for comparable tests at the fusion line.

The fracture surfaces of the Charpy impact samples tested at room temperature were characterised as shown in Figs. 9a \& 9b. All samples presented features that were indicative of ductile fracture, e.g. extensive microvoid coalescence in the tearing zone. Some inclusions were detected, which locally changed the fracture morphology to cleavage fracture. The fracture morphology for the $\mathrm{HHI}$ sample at a test temperature of $-20^{\circ} \mathrm{C}$ changed to be predominantly quasi cleavage, as is evident in Fig. 9c. Meanwhile, the morphology in the case of samples welded at LHI was dominated by dimple fracture, as can be seen in Fig. 9d.

Table 3: Base metal tensile properties before and after PWHT

\begin{tabular}{|c|c|c|}
\hline Property & F22 Steel (As received) & F22 Steel (after PWHT) \\
\hline Modulus of Elasticity (GPa) & - & 206 \\
\hline $0.2 \%$ Proof stress (MPa) & 634 & 598 \\
\hline UTS (MPa) & 765 & 719 \\
\hline Elongation (\%) & 26 & 23 \\
\hline Reduction in area (\%) & 79 & 77 \\
\hline
\end{tabular}


Table 4: Results of CTOD tests and Charpy Impact Tests

\begin{tabular}{|c|c|c|c|c|c|c|c|c|c|c|c|c|c|c|c|c|c|c|}
\hline & \multirow{2}{*}{\multicolumn{2}{|c|}{$\begin{array}{c}\text { Room temp. } \\
\text { F22 Parent } \\
\text { metal }\end{array}$}} & \multicolumn{8}{|c|}{ Room temp. } & \multicolumn{8}{|c|}{$-20^{\circ} \mathrm{C}$} \\
\hline & & & \multicolumn{4}{|c|}{$\begin{array}{c}\text { Sample M1 } \\
(\mathrm{HI}=2.3 \mathrm{~kJ} / \mathrm{mm})\end{array}$} & \multicolumn{4}{|c|}{$\begin{array}{c}\text { Sample M2 } \\
(\mathrm{HI}=1.1 \mathrm{~kJ} / \mathrm{mm})\end{array}$} & \multicolumn{4}{|c|}{$\begin{array}{c}\text { Sample M1 } \\
(\mathrm{HI}=2.3 \mathrm{~kJ} / \mathrm{mm})\end{array}$} & \multicolumn{4}{|c|}{$\begin{array}{c}\text { Sample M2 } \\
(\mathrm{HI}=1.1 \mathrm{~kJ} / \mathrm{mm})\end{array}$} \\
\hline & & & \multicolumn{2}{|c|}{ WM } & \multicolumn{2}{|c|}{ FL } & \multicolumn{2}{|c|}{ WM } & \multicolumn{2}{|c|}{ FL } & \multicolumn{2}{|c|}{ WM } & \multicolumn{2}{|c|}{ FL } & \multicolumn{2}{|c|}{ WM } & \multicolumn{2}{|c|}{ FL } \\
\hline & Av & SD & Av & SD & Av & SD & Av & SD & Av & SD & $\mathrm{Av}$ & SD & Av & SD & Av & SD & Av & SD \\
\hline Impact Energy (J) & 225 & 9.4 & 204 & 8.4 & 228 & 5.6 & 216 & 7.6 & 222 & 9.8 & 120 & 26.6 & 191 & 3.1 & 192 & 20 & 182 & 4.6 \\
\hline CTOD (ס) & 0.59 & 0.04 & 0.85 & 0.05 & 0.72 & 0.03 & 0.74 & 0.9 & 0.71 & 0.06 & 0.49 & 0.06 & 0.35 & 0.06 & 0.88 & 0.03 & 0.73 & 0.08 \\
\hline
\end{tabular}

Note: WM denotes weld metal, FL denotes fusion line, Av denotes average value and SD denotes

standard deviation.

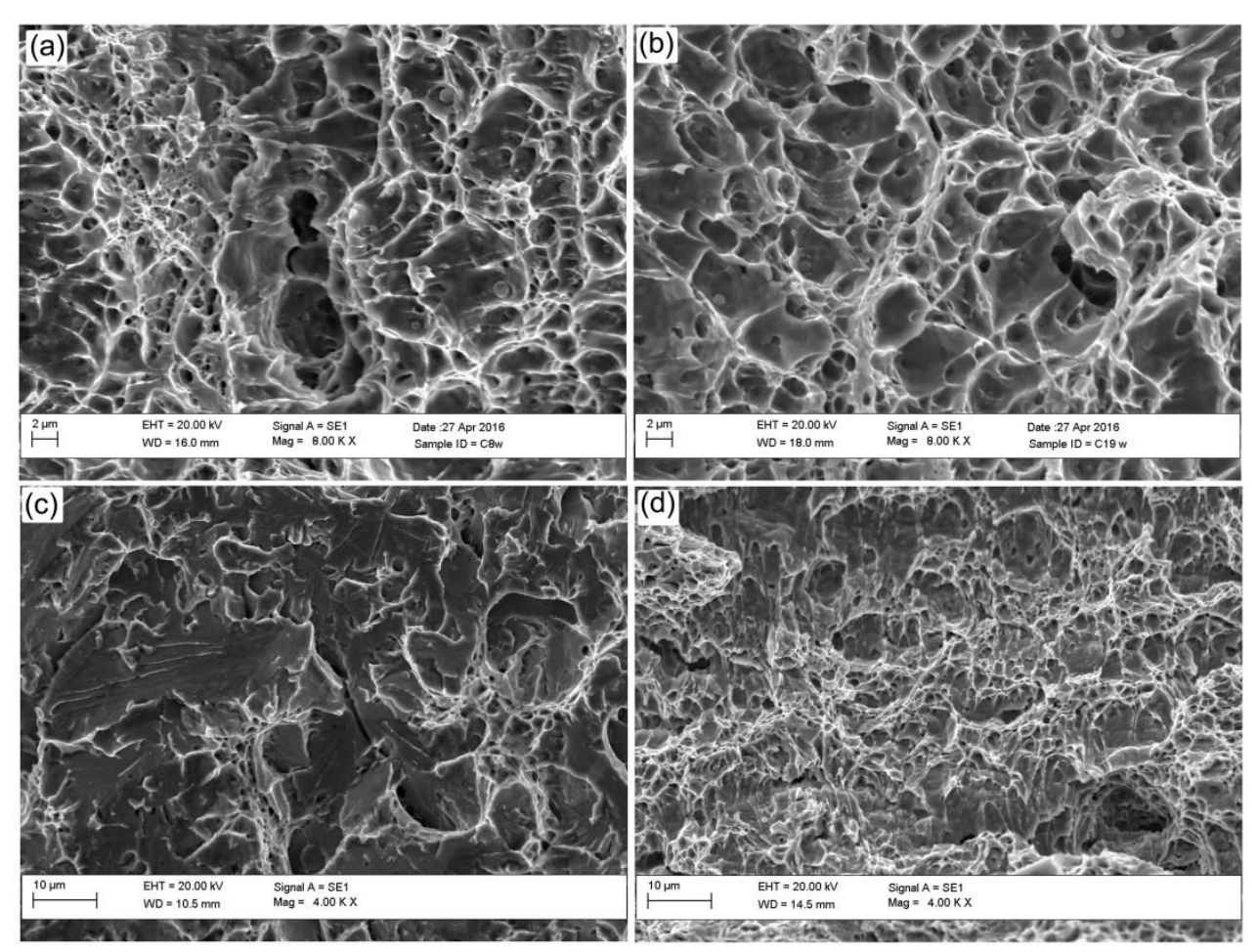

Figure 9: Fracture morphologies of Charpy impact specimens; (a) HHI sample at room temperature; (b) LHI sample at room temperature; (c) $\mathrm{HHI}$ sample at $-20^{\circ} \mathrm{C}$; (d) LHI sample at $-20^{\circ} \mathrm{C}$. 
The CTOD test results for the HHI sample show a loss in toughness of approximately $50 \%$ at $-20^{\circ} \mathrm{C}$, when compared with the results obtained at room temperature, both for samples notched in the weld metal and at the fusion line. The fracture surfaces of the CTOD test specimens were examined and, interestingly, they were all dominated by a dimple morphology, indicating high levels of ductile tearing (Fig. 10). The fractures in samples with notches at the FL progressed into the weld metal in all cases, following coarse columnar grains, irrespective of welding heat input and test temperature (Fig. 11), which is indicative of lower fracture toughness in the weld metal. The dimples on the samples welded with a HHI were much coarser than those for samples welded with a LHI. Furthermore, there also appeared to be a high concentration of inclusions, which appeared to be larger, in the case of the samples welded with a HHI. These inclusions were shown by energydispersive spectroscopy (EDS) to contain $\mathrm{Al}, \mathrm{Si}$, and $\mathrm{Mn}(\sim 45,30,25$ at. \% respectively). The presence of dimples on the fracture surfaces of the HHI samples at a test temperature of $-20^{\circ} \mathrm{C}$ (Fig. 10c) is a notable change from the cleavage fractures that were seen in the corresponding fracture surfaces for the Charpy impact specimens (Fig. 9c), and is likely to be related to the lower strain rates that apply in CTOD tests. It may also be an indication that, for the HHI weld, a test temperature of $-20^{\circ} \mathrm{C}$ is approaching the ductile-tobrittle transition temperature for the weld metal.

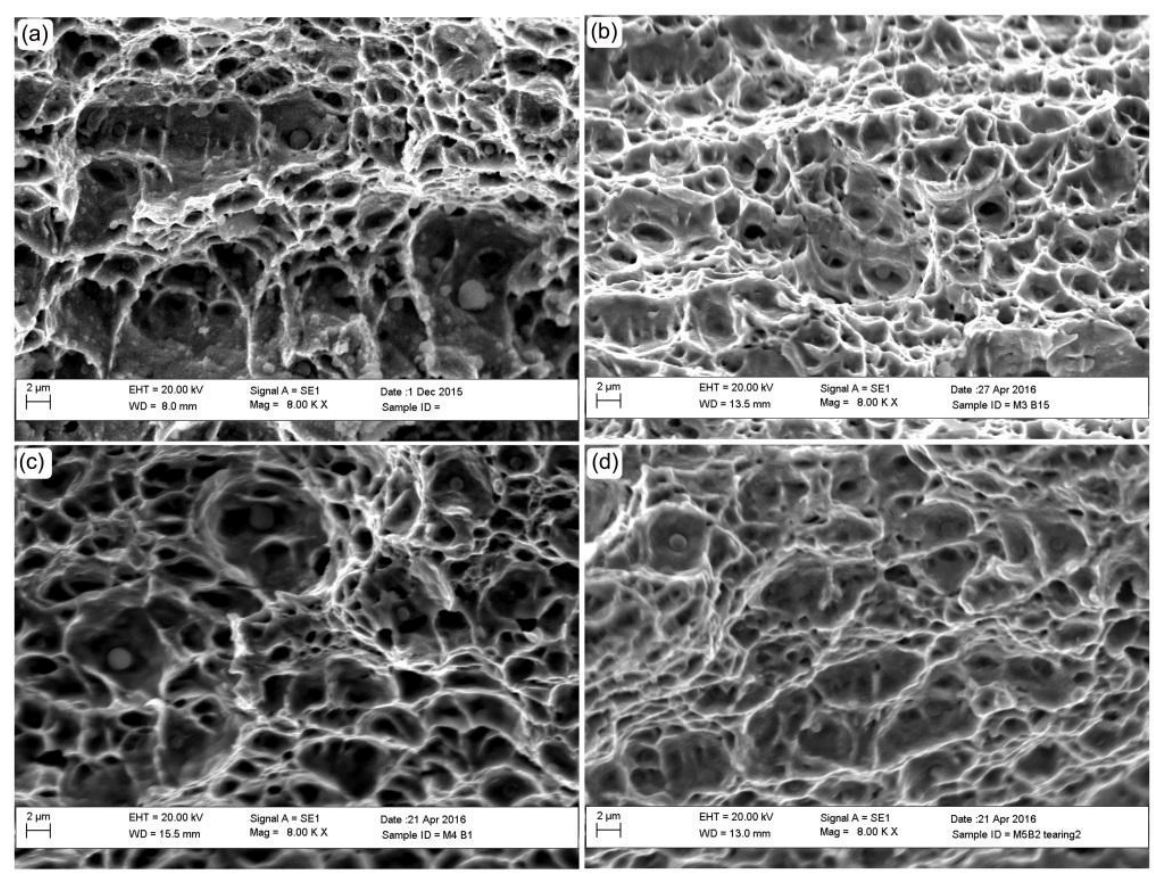

Figure 10: Fracture morphologies for CTOD specimens; (a) HHI sample at room temperature; (b) LHI sample at room temperature; (c) $\mathrm{HHI}$ sample at $-20^{\circ} \mathrm{C}$; (d) LHI sample at $-20^{\circ} \mathrm{C}$. 

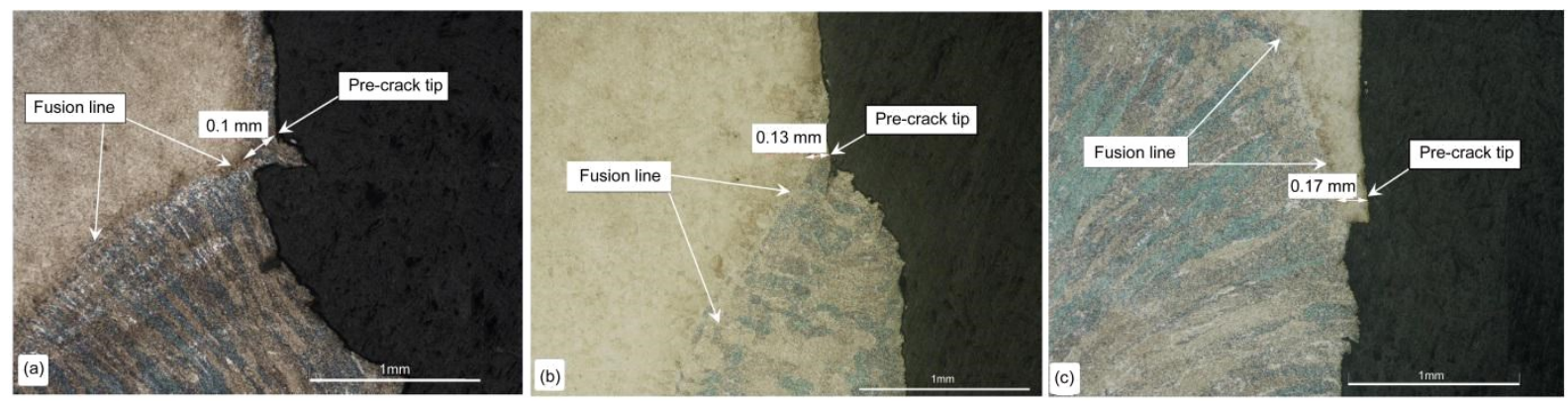

Fig. 11: Fracture paths after CTOD testing for samples notched at the FL: (a) HHI sample tested at room temperature; (b) HHI sample tested at $-20^{\circ} \mathrm{C}$; (c) LHI sample tested at $-20^{\circ} \mathrm{C}$. The direction of crack propagation is from top to bottom.

Al-Si-Mn inclusions were detected in most of the stable tearing regions that formed during the CTOD tests. Stable tearing regions are associated with decohesion around such inclusions during loading. Decohesion is followed by subsequent microvoid coalescence when the stresses ahead of the crack tip reach the threshold for nucleation of cleavage fracture. The size and distribution of inclusions are critical parameters in controlling the nucleation and growth of a crack at the onset of fracture. Therefore, control of weld chemistry and the PWHT procedure can be effective methods for improving weld fracture toughness.

The variability in mechanical properties and in the fracture toughness values of the samples in particular, appears to be related to inhomogeneities in the microstructure within the weld fusion zone. The fusion zone is composed of columnar prior-austenite grains, with room-temperature structures comprising phases such as ferrite, pearlite, bainite, martensite and retained austenite. In multipass welds, owing to the repeated thermal cycles that arise, different regions of the previously deposited weld metal are tempered to differing extents. Multipass welds of this type will, by nature, be inhomogeneous. However, it appears that the variability in toughness that arises from this heterogeneity can be mitigated to some degree by avoiding the use of a high weld heat input. 


\section{Conclusions}

The following conclusions can be drawn from this work:

- This work shows that there are possible causes for variability in the toughness of submerged arc welds involving F22 steel and low-alloy steel filler materials. This work therefore supports anecdotal observations that have been made in the oil and gas industry in which the possibility of variable weld toughness was noted.

- A marked reduction in the toughness of the welds made with a high heat input $(2.3 \mathrm{~kJ} / \mathrm{mm})$ was observed as the temperature was reduced from room temperature to $-20^{\circ} \mathrm{C}$. The reduction in fracture toughness was in the order of $40 \%$ and, in the case of the Charpy test results, a corresponding reduction in absorbed energy was accompanied by a significant increase in scatter.

- The weld metal (or fusion zone) is the region within the weldment that appears to be prone to variable toughness. This is evident from the significant reduction in fracture toughness values and absorbed energies that were seen in this region as the temperature was reduced from room temperature to $-20^{\circ} \mathrm{C}$. It is also consistent with observations of the fracture surfaces for the specimens targeting the fusion line, which revealed that cracks consistently deviated into the weld metal.

- It would appear that the toughness of submerged-arc welds between F22 steel and a low-alloy steel can be improved, and that variability in toughness can be ameliorated, through avoiding the use of a welding procedure with a high weld heat input. This is because, for high heat input welds, the shoulder of the ductile-to-brittle transition curve is likely to be encountered at temperatures in the vicinity of $0^{\circ} \mathrm{C}$.

\section{Acknowledgements}


The authors would like to acknowledge the funding and technical support from BP through the BP International Centre for Advanced Materials (BP-ICAM) which made this research possible. The authors would also like to thank Mr. Paul English for performing the welds.

\section{References}

1. DuPont J.N., Lippold J.C., Kiser S.D., Welding Metallurgy and Weldability of Nickel-Base Alloys, John Wiley \& Sons Inc., Hoboken, New Jersey, 2009.

1. Dodge M.F., Dong H.B., Gittos M.F., Mobberley T., Fusion Zone Microstructure Associated With Embrittlement Of Subsea Dissimilar Joints, Proceedings of the 33rd International Conference on Ocean, Offshore and Arctic Engineering OMAE2014, June 8-13, 2014, San Francisco, CA, USA.

2. Dodge M.F., Dong H.B., Milititsky M., Barnett R.P., Gittos M.F., Environment-Induced Cracking In Weld Joints In Subsea Oil And Gas Systems - Part II, Proceedings of the ASME 2013 32nd International Conference on Ocean, Offshore and Arctic Engineering OMAE2013, June 9-14, 2013, Nantes, France.

3. Jamey A. Fenske, Martin W. Hukle, Brian D. Newbury, J.R. Gordon, R. Noecker, I.M. Robertson, Hydrogen Induced Mechanical Property Behavior of Dissimilar Weld Metal Interfaces, ASME 2011 30th International Conference on Ocean, Offshore and Arctic Engineering, DOI: 10.1115/OMAE2011-50009.

4. Elboujdaini, M., Hydrogen-induced cracking and sulfide stress cracking. Uhlig's Corrosion Handbook. 2000, Wiley.

5. Hodgson D.K., Dai T., Lippold, J.C., Transformation and Tempering Behavior of the Heat-Affected Zone of 2.25Cr-1Mo Steel, Weld. J., 2015, Vol. 94, Issue 8, 250s-256s.

6. Peddle B.E. and Pickles C.A., Carbide and Hardness Development in the Heat-Affected Zone of Tempered and Postweld Heat-Treated 2.25Cr-1Mo Steel Weldments, Journal of Materials Engineering and Performance, 2000, Vol. 9, Issue 5, 477-488.

7. Vekeman J., Huysmans S., Cold weld repair of T91, OMMI, 2009, Vol. 6, Issue 1, April.

8. Coleman M.C., Parker J.D., Walters D.J., The Behaviour of Ferritic Weldments in Thick Section 12Cr12Mo14V Pipe at Elevated temperature, Int. J. Press. Vessels Pip., 1985,Vol. 18, Issue 4, 277-310. 
9. G.R. Speich, Tempering of low-carbon martensite, 1969, Trans. TMS-AIME, Vol. 245, 2553-2564.

10. Saroja S., Vijayalakshmi M., Raghunathan V.S., Effect of Prolonged Exposures of 9Cr-1Mo-0.07C Steel to Elevated Temperatures, Mater.Trans. JIM, 1993, Vol. 34, Issue 10, 901-906.

11. Caron R.N. and Krauss G., The tempering of Fe-C lath Martensite, Metall. Trans., 1972, Vol. 3, 23812389.

12. Parameswaran P., Vijayalakshmi M., Shankar P., Raghunathan V.S., Influence of Carbon Content on Microstructure and Tempering Behaviour of 2 1/4 Cr 1 Mo Steel, J. Mater. Sci., 1992, Vol. 27, 5426-5434.

13. Evans M. and Bailey N., Metallurgy of Basic Weld Metal, 1999, Abington Publishing.

14. T. Kasuya and Y. Hashiba, Carbon Equivalent to Assess Hardenability of Steel and Prediction of HAZ Hardness Distribution, Nippon Steel Technical Report No. 95, January 2007, pp. 53-61.

15. Moore P., Booth G., The Welding Engineer's Guide to Fracture and Fatigue, 2014, Woodhead Publishing Ltd.

16. Belforte D., Levitt M., The Industrial Laser Annual Handbook, New York, 1992/1993, Springer-Verlag. 